\title{
Caracterização da COVID-19 em crianças hospitalizadas
}

\author{
Characterization of COVID-19 in hospitalized children \\ Caracterización de COVID-19 en niños hospitalizados \\ Beatriz Rosana Gonçalves de Oliveira Toso ${ }^{1}$ (D) https://orcid.org/0000-0001-7366-077x \\ Maria Aparecida Munhoz Gaíva² (D) https://orcid.org/0000-0002-8666-9738 \\ Francisneide Gomes Pego do Nascimento ${ }^{3}$ (D) https://orcid.org/0000-0002-0130-0385 \\ Myriam Aparecida Mandetta ${ }^{4}$ (D) https://orcid.org/0000-0003-4399-2479
}

\section{Resumo}

Objetivo: Identificar as evidências disponíveis sobre as caraterísticas epidemiológicas, clínicas e medidas terapêuticas da COVID-19 em crianças hospitalizadas.

Métodos: Revisão integrativa de literatura, realizada em junho de 2020, mediante busca nas bases de dados Web of Science, CINAHL, MEDLINE e SCOPUS. A coleta de dados foi realizada em matriz própria seguindo a orientação PRISMA. Foram incluídos 19 artigos e submetidos a análise temática.

Resultados: Predominaram crianças do sexo masculino e menores de um ano. A transmissão familiar foi mais comum, condições pré-existentes foram identificadas e os óbitos ocorreram em menor proporção comparado aos adultos. As manifestações clínicas predominantes incluíram febre, tosse, dor de garganta, falta de ar, náuseas, vômito, dor abdominal e diarreia. A terapêutica incluiu isolamento e os tratamentos foram sintomáticos e experimentais.

Conclusão: A COVID-19 acomete mais crianças do sexo masculino, menores de um ano, com predomínio de sinais clínicos respiratórios e tratamento experimental.

\section{Abstract}

Objective: To identify the available evidence on the epidemiological, clinical and therapeutic measures of COVID-19 in hospitalized children.

Methods: Integrative literature review, conducted in June 2020, by searching the Web of Science, CINAHL, MEDLINE and SCOPUS databases. Data collection was carried out in a proper matrix following the PRISMA guidance. The analysis of the 19 included studies was thematic.

Results: Male children and children under one year old predominated. Family transmission was more common, pre-existing conditions were identified and deaths occurred to a lesser extent compared to adults. The predominant clinical manifestations were fever, cough, sore throat, shortness of breath, nausea, vomiting, abdominal pain, and diarrhea. Therapy included isolation and treatments were symptomatic and experimental.

Conclusion: COVID-19 affects more male children, younger than one year, with a predominance of clinical respiratory signs and experimental treatment.

\section{Resumen}

Objetivo: Identificar la evidencia disponible sobre las medidas epidemiológicas, clínicas y terapéuticas de COVID-19 en niños hospitalizados.

Métodos: Revisión integrativa de la literatura, realizada en junio de 2020, buscando en las bases de datos de Web of Science, CINAHL, MEDLINE y SCOPUS. La recopilación de datos se llevó a cabo en una matriz propia siguiendo la guía PRISMA. El análisis de los 19 estudios incluidos fue temático.

Resultados: Predominaron niños varones y menores de un año. La transmisión familiar fue más común, se identificaron condiciones preexistentes y las muertes ocurrieron en menor medida en comparación con los adultos. Las manifestaciones clínicas predominantes fueron fiebre, tos, dolor de garganta, dificultad para respirar, náuseas, vómitos, dolor abdominal y diarrea. La terapia incluyó aislamiento y los tratamientos fueron sintomáticos y experimentales.

Conclusión: COVID-19 afecta a más niños varones, menores de un año, con predominio de signos respiratorios clínicos y tratamiento experimental.

\section{Como citar:}

Toso BR, Gaíva MA, Nascimento FG, Mandetta MA. Caracterização da COVID-19 em crianças hospitalizadas. Rev Soc Bras Enferm Ped. 2020;20(Especial COVID-19):36-48.

\footnotetext{
${ }^{1}$ Universidade Estadual do Oeste do Paraná, Cascavel, PR, Brasil.

${ }^{2}$ Universidade Federal de Mato Grosso, Cuiabá, MT, Brasil.

${ }^{3}$ Universidade Federal de Mato Grosso do Sul, Campo Grande, MS, Brasil.

${ }^{4}$ Escola Paulista de Enfermagem, Universidade Federal de São Paulo, São Paulo, SP, Brasil.

Conflitos de interesse: nada a declarar.

Submetido: 17 de Julho de 2020 | Aceito: 18 de Setembro de 2020

Autor correspondente: Myriam Aparecida Mandetta | E-mail: mymandetta@gmail.com

DOI: http://dx.doi.org/10.31508/1676-3793202000000125
}

\section{Keywords}

Pediatric nursing; Coronavirus infections; Child; Health profile; COVID-19

\section{Descriptores}

Enfermería pediátrica; Infecciones por coronavirus; Niño; Perfil de salud; COVID-19 


\section{Introdução}

A Organização Mundial da Saúde (OMS) foi notificada em dezembro de 2019, sobre 44 casos de pneumonia de etiologia desconhecida, associada à cidade de Wuhan, província de Hubei, China. A maioria dos pacientes teve contato com o mercado de frutos do mar e animais vivos Huanan South China Seafood Market. A OMS anunciou que um novo Coronavírus havia sido identificado nesses pacientes. Desde então, o surto aumentou rapidamente, com a OMS declarando emergência de saúde pública de preocupação internacional em 30 de janeiro de 2020 e, em seguida, declarando formalmente uma pandemia, em 11 de março de 2020.(1)

A doença do Coronavírus 2019 (COVID-19) é caracterizada como uma infecção respiratória aguda potencialmente grave, denominada síndrome respiratória aguda grave Coronavírus 2 (SARS-CoV-2). A apresentação clínica tem sido de infecção respiratória cujos sintomas variam de doença leve e comum semelhante ao resfriado, até pneumonia viral grave, que leva à síndrome do desconforto respiratório agudo, potencialmente fatal. ${ }^{(2,3)}$

As informações disponíveis sobre a gravidade e comorbidades de crianças e adolescentes com COVID-19 são mais inconsistentes quando comparadas com dados de pessoas adultas com a doença ${ }^{(4)}$, dificultando detectar fatores de risco para as complicações e mortalidade específicas naquela faixa etária da população ${ }^{(4)}$. Pesquisadores ${ }^{(5)}$ indicam que a infecção em crianças e adolescentes pelo vírus SARS-COV-2, se caracteriza, na maioria das vezes, por manifestações leves ou moderadas, mas em alguns casos pode levar a hospitalização ou até mesmo cuidados intensivos.

As taxas de letalidade e mortalidade tem sido variáveis ao redor do mundo, a depender das medidas de contenção de transmissão adotadas pelos diferentes países, sendo uma ameaça importante e urgente à saúde global. Desde o surto no início de dezembro de 2019, o número de pacientes confirmados para a doença ultrapassou 13.771.805 ao redor do mundo, e o número de pessoas infectadas é provavelmente muito maior, devido à ausência de testagem para todos os possíveis casos. Mais de 589.954 pessoas morreram de infecção pela COVID-19 (até 17 de julho de 2020). ${ }^{(6)}$

A disseminação de pessoa para pessoa foi confirmada em ambientes comunitários e de saúde, com a transmissão local agora ocorrendo em muitos países ao redor do mundo. Não se pode afirmar com certeza os mecanismos pelos quais o vírus se espalha entre as pessoas, mas a transmissão em cadeia envolvendo vários locais é cada vez mais reconhecida. As evidências disponíveis indicam que a transmissão humana ocorre através do contato próximo com gotículas respiratórias produzidas quando uma pessoa exala, espirra ou tosse; via contato direto com pessoas infectadas; através do contato com fômites; e, a transmissão aérea foi recentemente informada como possibilidade. ${ }^{(7)}$

Supostamente, em crianças, tanto a letalidade quanto a mortalidade são reduzidas, embora haja relatos de contaminação e hospitalização nessa faixa etária. Na China, onde os primeiros casos da COVID-19 foram reportados, $1,2 \%$ dos casos foram em pessoas de 10 a 19 anos e 0,9\% em menores de dez anos. Apenas um óbito foi notificado em adolescente. Em análise de 2.143 casos pediátricos suspeitos e confirmados de SARS-CoV-2 na China, o grupo de menos de dez anos teve maior risco de desenvolver a doença de forma grave $(10,6 \%)$, comparado com faixa etária de 11 a 15 anos $(4,1 \%)$ e 16 anos e mais $(3,0 \%) \cdot{ }^{(8)}$

No Brasil, até 17 de julho de 2020, ocorreram 2.114.738 confirmações de pessoas com COVID-19 e 76.822 morreram em decorrência dessa doença. ${ }^{(6)}$ Os casos têm tido aumento diário e o país ainda não atingiu o chamado pico da curva da doença, o que preocupa a população e as autoridades sanitárias. Em crianças, embora a literatura( ${ }^{(8)}$ indique um risco reduzido em comparação aos adultos, até o momento ocorreram 163 (0,3\%) óbitos no país. ${ }^{(6)}$

No entanto, as informações disponíveis sobre a gravidade e comorbidades de crianças e adolescentes com COVID-19 são mais inconsistentes quando comparadas com dados de pessoas adultas com a doença, ${ }^{(9,10)}$ o que dificulta detectar fatores de risco para as complicações e mortalidade específicas naquela faixa etária da população. ${ }^{(10)} \mathrm{Em}$ tal contexto, conhecer as características epidemiológicas, clinicas e medidas terapêuticas da COVID-19 em crianças infectadas pelo vírus SARS-CoV-2 torna-se essencial para compreender como a doença acomete esse grupo etário, além subsidiar ações e estratégias de controle, tratamento e reabilitação nesta população.

Nesse sentido, para o enfrentamento do novo cenário imposto pela COVID-19 e especificamente no cui- 
dado as crianças, é necessário conhecer os sinais e sintomas da doença e as medidas terapêuticas adotadas, no sentido de informar a comunidade científica e profissionais de saúde/enfermeiros sobre o que foi produzido até o momento em relação a esses aspectos, favorecendo um cuidado atualizado e baseado em evidências.

Assim, o estudo tem por objetivo identificar as evidências disponíveis sobre as caraterísticas epidemiológicas, clínicas e medidas terapêuticas da COVID-19 em crianças hospitalizadas.

\section{Métodos}

Revisão integrativa, a qual consiste na construção de ampla análise da literatura, para obter o melhor entendimento possível de um determinado fenômeno, baseando-se em estudos anteriores. Para seu desenvolvimento, primeiro se determina o objetivo específico, formulam-se os questionamentos a serem respondidos, se realiza a busca para identificar e coletar o máximo de estudos relevantes, de acordo com os critérios de inclusão e exclusão estabelecidos. ${ }^{(11)}$

No método para a revisão integrativa, seguem-se seis fases distintas. São elas: 1 à : identificação do tema e elaboração da questão de pesquisa; $2^{\mathrm{a}}$ : estabelecimento dos critérios de inclusão e exclusão de estudos; $3^{\text {an}}$ : definição das informações a serem extraídas dos estudos; $4^{\mathrm{a}}$ : avaliação dos estudos incluídos; $5^{\mathrm{a}}$ : interpretação dos resultados; $6^{a}$ : apresentação da síntese do conhecimento. ${ }^{(11)}$

Na primeira etapa, definiu-se a seguinte questão norteadora: Quais são as caraterísticas epidemiológicas, clínicas e medidas terapêuticas da COVID-19 em crianças hospitalizadas? Para responder à questão, foi realizada busca da literatura em junho de 2020, nas seguintes Bases de Dados: Medical Literature Analysis and Retrieval Sistem on-line (MEDLINE/Pubmed), Current Nursing and Allied Health Literature (CINAHL), SCOPUS e Web of Science. A segunda etapa foi realizada por dois pesquisadores independentes para definir os estudos incluídos.

Os Descritores em Ciências da Saúde (DeCS) em português e seus correspondentes em inglês e espanhol foram: COVID-19, Coronavírus, Criança, Neonato, hospitalização, tratamento, cuidado de enfermagem. COVID-19, coronavirus, child, neonato, hospitalization, treatment, care nursing. COVID-19, coronavirus, niño, recién nacido, hospitalización, tratamento, cuidado de enfermería. A estratégia de busca para obtenção dos estudos primários foi realizada por meio de arranjos entre descritores e operadores booleanos (AND) com parênteses e aspas, conforme o quadro 1 .

Quadro 1. Descritores e cruzamentos utilizados nas bases de dados

\begin{tabular}{|l|l|l|}
\hline $\begin{array}{l}\text { Base de dados } \\
\text { (Total textos } \\
\text { selecionados para } \\
\text { leitura dos resumos) }\end{array}$ & Cruzamento-descritores & $\begin{array}{l}\text { Artigos } \\
\text { selecionados }\end{array}$ \\
\hline $\begin{array}{l}\text { PUBMED } \\
(148)\end{array}$ & $\begin{array}{l}\text { "COVID-19 AND Children, infant, } \\
\text { newborn" AND “hospitalization" AND } \\
\text { "Treatment AND Care nursing" }\end{array}$ & 33 \\
\hline $\begin{array}{l}\text { CINAHL } \\
(30)\end{array}$ & $\begin{array}{l}\text { "COVID-19 AND Children, infant, } \\
\text { newborn" AND “hospitalization" AND } \\
\text { "Treatment AND Care nursing" }\end{array}$ & 1 \\
\hline $\begin{array}{l}\text { SCOPUS } \\
(180)\end{array}$ & $\begin{array}{l}\text { "COVID-19 AND Children, infant, } \\
\text { newborn" AND “hospitalization" AND } \\
\text { "Treatment AND Care nursing" }\end{array}$ & 7 \\
\hline $\begin{array}{l}\text { Web of Science } \\
(12)\end{array}$ & $\begin{array}{l}\text { "COVID-19 AND Children, infant, } \\
\text { newborn" AND “hospitalization" AND } \\
\text { "Treatment AND Care nursing" }\end{array}$ & 1 \\
\hline Total & & 42 \\
\hline
\end{tabular}

Os critérios de inclusão dos estudos foram: artigos científicos de pesquisas primárias, revisões sistemáticas e estudos de casos disponíveis na íntegra em qualquer idioma, publicados a partir de dezembro de 2019 até o final do mês de junho de 2020, momento em que a busca foi encerrada. Além disso, utilizou-se como critérios de inclusão estudos cujos participantes fossem crianças hospitalizadas e com diagnóstico laboratorial confirmado de COVID-19. Os critérios de exclusão foram publicações que não respondiam à questão de pesquisa, editoriais, carta ao editor, consensos, guidelines e as duplicadas.

Dessa forma, as referências encontradas tiveram seus títulos e resumos lidos exaustivamente com o intuito de verificar se respondiam à questão do estudo. Após essa etapa, 42 artigos foram selecionados para leitura e dentre eles, 19 compuseram a amostra final (Figura 1).

Na coleta de dados dos artigos selecionados para leitura na íntegra foi aplicado instrumento elaborado pelas pesquisadoras e a análise crítica dos estudos se deu por análise temática indutiva em seis etapas: familiarização com os dados; geração de códigos iniciais; pesquisa de temas por meio da análise dos códigos definidos; revisão dos temas; definição e nomeação dos temas; e, por fim, produção do relatório. ${ }^{(11)}$

Por fim, procedeu-se ao agrupamento e síntese dos resultados com o objetivo principal de descrever as evidências disponíveis e responder à questão de pesquisa. 


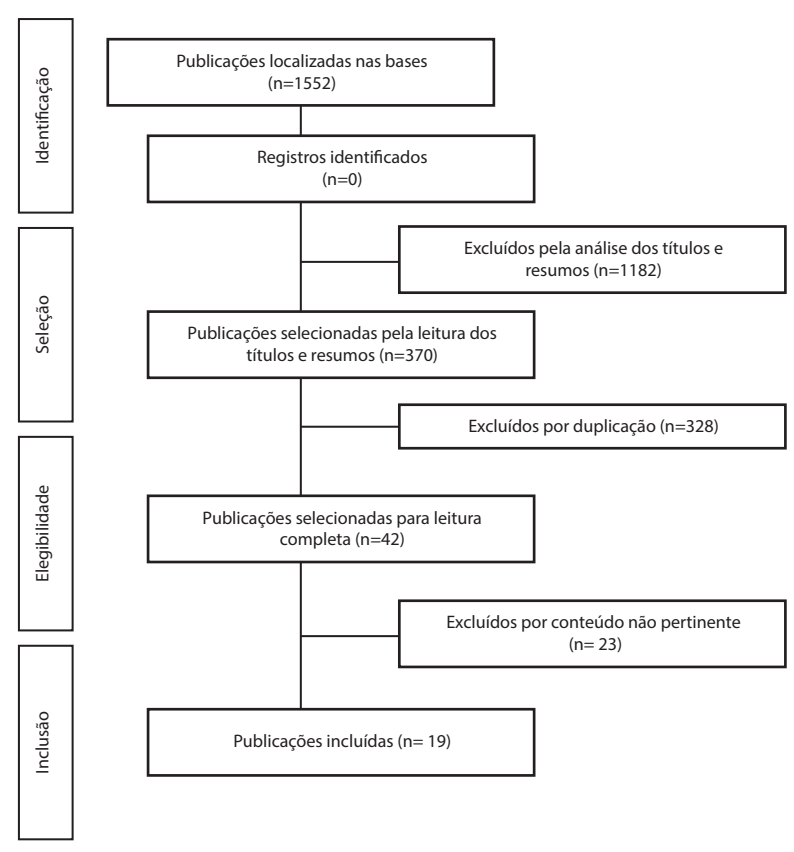

Figura 1. Diagrama da pesquisa

\section{Resultados}

A maior parte dos estudos foi desenvolvida na China $(n=8)$, seguido pelos EUA $(n=3)$, Itália $(n=2)$ e Irã $(n=2)$, e outros países com apenas um (Turquia, Alemanha, Coreia do Sul e Índia). Quanto ao tipo de estudo, houve predomínio de revisão da literatura $(5 ; 23 \%)$, estudos de casos (4;18\%), estudos retrospectivos (4; $18 \%$ ), revisões sistemáticas ( $2 ; 9 \%)$, estudo multicêntrico transversal, revisão de dados multicêntrico, epidemiológico e relato semanal de base de dados, com um artigo de cada. Quanto ao número de participantes variou de um, em estudos de caso a 2.914 crianças nas revisões de literatura. As características das publicações estão descritas no quadro 2.

Em relação ao perfil epidemiológico das crianças com COVID-19, a idade variou desde recém-nascidos a crianças de um ano até adolescentes com 18 anos. Houve predomínio do sexo masculino. ${ }^{(10-24)}$ Quanto a forma de contaminação das crianças, os estudos mostraram a predominância da transmissão familiar, seguida pela transmissão comunitária. ${ }^{(10-24)}$ Estudos relataram que aproximadamente $20 \%$ das crianças tinham morbidades prévias, dentre elas, problemas respiratórios, inclusive asma, epilepsia, câncer, problemas cardíacos e imunossupressão. ${ }^{(10-24)}$ Os menores de um ano foram os que mais necessitaram de hospitalização, a internação em UTI foi considerada baixa, assim como o número de óbitos (Quadro 3).

As manifestações clínicas mais frequentes, em aproximadamente 50 a $70 \%$ das crianças, incluíram febre, tosse seca, falta de ar/dispneia. Menos frequentes foram descritas mialgia, rinorreia, congestão nasal, dor de garganta, dor de cabeça, tontura, náusea, vômito, dor abdominal e diarreia. Muitas crianças estavam assintomáticas quando o diagnóstico foi confirmado. Os marcadores inflamatórios proteína $\mathrm{C}$ reativa e procalcitonina estavam aumentados nas crianças. Houve ainda relato de crianças co-infectadas com outros vírus, incluindo adenovírus e vírus sincicial respiratório.

As medidas terapêuticas mais utilizadas foram: monitoramento contínuo, fluidoterapia, oxigenoterapia inalatória e ventilação não invasiva. A terapêutica mais frequente foi com antiviral, interferon, imunossupressor, seguido de antibioticoterapia, sendo citados vancomicina e amicacina, oseltamivir e tratamentos experimentais para infecção por SARS-CoV-2 incluindo lopinavir, ritonavir, hidroxicloroquina e/ou azitromicina e claritromicina, traqueostomia e terapia de substituição renal. A quarentena foi utilizada na maioria dos casos de hospitalização. No quadro 3, são apresentados os dados epidemiológicos, as manifestações clínicas e medidas terapêuticas. 
Quadro 2. Caracterização dos estudos analisados de acordo com o título, autores, país, tipo de estudo e número de participantes (crianças) $(\mathrm{n}=19)$

\begin{tabular}{|c|c|c|c|c|c|}
\hline Autor/ano de publicação & Título & Periódico & País & Tipo de estudo & $\mathrm{n}^{0}$ de participantes \\
\hline Zheng F, et al., 2020(10) & $\begin{array}{l}\text { Clinical characteristics of children with } \\
\text { Coronavirus disease } 2019 \text { in Hubei, China. }\end{array}$ & $\begin{array}{l}\text { Current Medical } \\
\text { Science }\end{array}$ & China & $\begin{array}{l}\text { Estudo documental } \\
\text { retrospectivo de } \\
\text { série de casos }\end{array}$ & 25 crianças $(1 \mathrm{~m}-14 \mathrm{a})$ \\
\hline $\begin{array}{l}\text { Bal, Zş; Kurugöl, Z; Özkınay, F. } \\
2020^{(12)}\end{array}$ & Clinical Features of COVID-19 in Children. & $\begin{array}{l}\text { Turkey Journal of } \\
\text { Pediatric Research }\end{array}$ & Turquia & Revisão literatura & $\begin{array}{l}\text { Crianças e } \\
\text { adolescentes }\end{array}$ \\
\hline $\begin{array}{l}\text { Armann, JP, Diffloth N, Simon } \\
\text { A, Doenhardt M, Hufnagel M, } \\
\text { Trotter A, et al., 2020(13) }\end{array}$ & $\begin{array}{l}\text { Hospital admission in children and adolescents } \\
\text { with COVID-19. }\end{array}$ & $\begin{array}{l}\text { Deutsches Arzteblatt } \\
\text { international }\end{array}$ & Alemanha & Epidemiológico & $\begin{array}{l}128 \text { crianças e } \\
\text { adolescentes }\end{array}$ \\
\hline Patel NA. $2020^{(14)}$ & $\begin{array}{l}\text { Pediatric COVID-19: systematic review of the } \\
\text { literature. }\end{array}$ & $\begin{array}{l}\text { American Journal of } \\
\text { Otolaryngology }\end{array}$ & $\begin{array}{l}\text { Estados } \\
\text { Unidos da } \\
\text { América } \\
\end{array}$ & Revisão sistemática & $\begin{array}{l}2.914 \text { crianças e } \\
\text { adolescentes }\end{array}$ \\
\hline $\begin{array}{l}\text { White A, Mukherjee P, } \\
\text { Stremming J, Sherlock LG, } \\
\text { Reynolds RM, Smith D, et al., } \\
2020^{(15)}\end{array}$ & $\begin{array}{l}\text { Neonates hospitalized with community-acquired } \\
\text { SARS-CoV-2 in a Colorado Neonatal Intensive } \\
\text { Care Unit. }\end{array}$ & Neonatology & $\begin{array}{l}\text { Estados } \\
\text { Unidos da } \\
\text { América }\end{array}$ & Estudo de casos & 3 RN (17-33d) \\
\hline $\begin{array}{l}\text { Balasubramanian S, Rao } \\
\text { NM, Goenka A, Roderick M, } \\
\text { Ramanan AV. 2020 } \\
\end{array}$ & $\begin{array}{l}\text { Coronavirus Disease } 2019 \text { (COVID-19) in Children } \\
\text { - What We Know So Far and What We Do Not. }\end{array}$ & Indian Pediatrics & Índia & Revisão literatura & $\begin{array}{l}\text { Crianças e } \\
\text { adolescentes }\end{array}$ \\
\hline $\begin{array}{l}\text { CDC COVID-19 Response } \\
\text { Team. 2020(17) }\end{array}$ & $\begin{array}{l}\text { Coronavirus Disease } 2019 \text { in Children - United } \\
\text { States, February 12-April 2, } 2020 .\end{array}$ & $\begin{array}{l}\text { Morbidity and } \\
\text { Mortality Weekly } \\
\text { Report }\end{array}$ & $\begin{array}{l}\text { Estados } \\
\text { Unidos da } \\
\text { América }\end{array}$ & \begin{tabular}{|l|} 
Relatório \\
semanal/estudo \\
epidemiológico \\
\end{tabular} & $\begin{array}{l}2.572 \text { crianças e } \\
\text { adolescentes }\end{array}$ \\
\hline $\begin{array}{l}\text { Choi SH, Kim HW, Kang JM, } \\
\text { Kim DH, Cho EY. 2020(18) }\end{array}$ & $\begin{array}{l}\text { Epidemiology and clinical features of coronavirus } \\
\text { disease } 2019 \text { in children. }\end{array}$ & \begin{tabular}{|l|} 
Clinical and \\
Experimental \\
Pediatrics
\end{tabular} & $\begin{array}{l}\text { Coréia do } \\
\text { Sul }\end{array}$ & Revisão literatura & $\begin{array}{l}\text { Crianças e } \\
\text { adolescentes }\end{array}$ \\
\hline $\begin{array}{l}\text { De Rose DU, Piersigilli F, } \\
\text { Ronchetti MP, Santisi A, Bersani } \\
\text { I, Dotta A, et al., 2020 }\end{array}$ & $\begin{array}{l}\text { Novel Coronavirus disease (COVID-19) in } \\
\text { newborns and infants: what we know so far. }\end{array}$ & $\begin{array}{l}\text { Italian Journal of } \\
\text { Pediatrics }\end{array}$ & Itália & Revisão literatura & $\mathrm{RN}$ e crianças $<6 \mathrm{~m}$ \\
\hline $\begin{array}{l}\text { Garazzino S, Montagnani C, } \\
\text { Donà D, Meini A, Felici E, } \\
\text { Vergine G, etr al., } 2020^{(20)}\end{array}$ & $\begin{array}{l}\text { Multicentre italian study of SARS-CoV-2 infection } \\
\text { in children and adolescents, preliminary data as } \\
\text { at } 10 \text { April } 2020 .\end{array}$ & Euro Surveillance & Itália & $\begin{array}{l}\text { Revisão Dados } \\
\text { Multicêntrico }\end{array}$ & 168 crianças \\
\hline $\begin{array}{l}\text { Kamali Aghdam M, Jafari N, } \\
\text { Eftekhari K. } 2020^{(21)}\end{array}$ & $\begin{array}{l}\text { Novel coronavirus in a 15-day-old neonate with } \\
\text { clinical signs of sepsis, a case report. }\end{array}$ & Infectious Diseases & Irã & Estudo de caso & $1 \mathrm{RN}$ com $15 \mathrm{~d}$ \\
\hline $\begin{array}{l}\text { Panahi L, Amiri M, Pouy S. } \\
2020^{(22)}\end{array}$ & $\begin{array}{l}\text { Clinical characteristics of COVID-19 infection in } \\
\text { newborns and pediatrics: a Systematic Review. }\end{array}$ & $\begin{array}{l}\text { Archives of } \\
\text { Academic } \\
\text { Emergency Medicine }\end{array}$ & Irã & Revisão sistemática & 2228 crianças \\
\hline $\begin{array}{l}\text { Sun D, Chen X, Li H, Lu XX, Xiao } \\
\text { H, Zhang FR, Liu ZS. } 2020^{(23)}\end{array}$ & $\begin{array}{l}\text { SARS-CoV-2 infection in infants under } 1 \text { year of } \\
\text { age in Wuhan City, China. }\end{array}$ & $\begin{array}{l}\text { World Journal of } \\
\text { Pediatrics }\end{array}$ & China & $\begin{array}{l}\text { Estudo documental } \\
\text { retrospectivo }\end{array}$ & 36 crianças $<1 a$ \\
\hline $\begin{array}{l}\text { Wang J, Wang D, Chen GC, Tao } \\
\text { XW, Zeng LK. 2020(24) }\end{array}$ & $\begin{array}{l}\text { SARS-CoV-2 infection with gastrointestinal } \\
\text { symptoms as the first manifestation in a neonate. }\end{array}$ & $\begin{array}{l}\text { Chinese Journal } \\
\text { of Contemporary } \\
\text { Pediatrics }\end{array}$ & China & Estudo de caso & $1 \mathrm{RN}$ \\
\hline $\begin{array}{l}\text { Xia W, Shao J, Guo Y, Peng X, Li } \\
\text { Z, Hu D. 2020(25) }\end{array}$ & $\begin{array}{l}\text { Clinical and CT features in pediatric patients with } \\
\text { COVID-19 infection: different points from adults. }\end{array}$ & \begin{tabular}{|l} 
Pediatric \\
Pulmonology
\end{tabular} & China & $\begin{array}{l}\text { Estudo documental } \\
\text { retrospectivo }\end{array}$ & 20 crianças \\
\hline $\begin{array}{l}\text { Xiong ப, Zhou MY, He XQ, Wu Y, } \\
\text { Xie XL. 2020(26) }\end{array}$ & $\begin{array}{l}\text { The role of human Coronavirus infection in } \\
\text { pediatric acute gastroenteritis. }\end{array}$ & $\begin{array}{l}\text { The Pediatric } \\
\text { Infectious Disease } \\
\text { Journal }\end{array}$ & China & Revisão literatura & $\begin{array}{l}\text { Crianças e } \\
\text { adolescentes }\end{array}$ \\
\hline $\begin{array}{l}\text { Zeng L, Tao X, Yuan W, et al., } \\
2020^{(27)}\end{array}$ & First case of neonate with COVID-19 in China. & $\begin{array}{l}\text { Chinese Journal of } \\
\text { Pediatrics }\end{array}$ & China & Estudo de caso & $1 \mathrm{RN}$ \\
\hline $\begin{array}{l}\text { Zhang, C., Gu, J., Chen, Q., } \\
\text { Deng, N., Li, J., Huang, L., Zhou, } \\
\text { X. 2020(28) }\end{array}$ & $\begin{array}{l}\text { Clinical and epidemiological characteristics of } \\
\text { pediatric SARS-CoV-2 infections in China: A } \\
\text { multicenter case series. }\end{array}$ & PLOS MEDICINE & China & $\begin{array}{l}\text { Retrospectivo } \\
\text { observacional } \\
\text { multicêntrico de } \\
\text { série de casos }\end{array}$ & 34 crianças \\
\hline $\begin{array}{l}\text { Zhou Y, Yang GD, Feng K, Huang } \\
\text { H, Yun YX, Mou XY, Wang LF. } \\
2020^{(29)}\end{array}$ & $\begin{array}{l}\text { Clinical features and chest CT findings of } \\
\text { coronavirus disease } 2019 \text { in infants and Young } \\
\text { children. }\end{array}$ & $\begin{array}{l}\text { Zhongguo Dang Dai } \\
\text { Er Ke Za Zhi. }\end{array}$ & China & $\begin{array}{l}\text { Estudo documental } \\
\text { retrospectivo }\end{array}$ & 9 crianças \\
\hline
\end{tabular}


Quadro 3. Dados epidemiológicos, manifestações clínicas e medidas terapêuticas

\begin{tabular}{|c|c|c|c|c|}
\hline Autor/Ano & Objetivo & Epidemiologia & Manifestações clínicas & Medidas terapêuticas \\
\hline $\begin{array}{l}\text { Zheng F, Liao C, } \\
\text { Fan QH, Chen HB, } \\
\text { Zhao XG, Xie ZG, et } \\
\text { al., } 2020^{(10)}\end{array}$ & \begin{tabular}{|l|} 
Descrever as \\
características \\
clínicas de \\
25 pacientes \\
pediátricos \\
hospitalizados com \\
covID-19.
\end{tabular} & $\begin{array}{l}\text { - } 14 \text { meninos e } 11 \text { meninas (1:27), } \\
\text { idade média } 3 \text { anos, dois somente } \\
\text { com doença prévia, ambos com } \\
\text { má-formação cardíaca congênita } \\
\text { e um acrescido de má nutrição e } \\
\text { síndrome metabólica hereditária; } \\
\text { - } 21 \text { tiveram contato } \\
\text { epidemiológico. }\end{array}$ & $\begin{array}{l}\text { - Infecção do trato respiratório superior (8) } \\
\text { e pneumonia leve (15); } \\
\text { - Os sintomas mais comuns foram febre } \\
(52 \%) \text {, tosse seca (44\%), diarreia (12\%), } \\
\text { congestão nasal (8\%), dispneia (8\%), dor } \\
\text { abdominal (8\%) e vômito (8\%). }\end{array}$ & $\begin{array}{l}\text { - Todos ficaram em quarentena; } \\
\text { - } 12 \text { (48\%) receberam terapia antiviral } \\
\text { (Interferon, arbidol, oseltamivir, } \\
\text { lopinavir/litonavir), sendo o interferon o } \\
\text { mais usado; } \\
\cdot 13 \text { (56\%) receberam antibióticos } \\
\text { empíricos; } \\
-2 \text { pacientes foram para unidade de } \\
\text { terapia intensiva pediátrica (UTIP), } \\
\text { receberam ventilação mecânica } \\
\text { invasiva, corticosteróides sistemáticos e } \\
\text { imunoglobulina intravenosa; } \\
\cdot 1 \text { deles recebeu terapia renal } \\
\text { substitutiva. }\end{array}$ \\
\hline $\begin{array}{l}\text { Bal ZŞ, Kurugöl Z, } \\
\text { Özkınay F. 2020(12) }\end{array}$ & $\begin{array}{l}\text { Resumir as } \\
\text { características } \\
\text { clínicas da SARS- } \\
\text { CoV-2 em crianças. }\end{array}$ & $\begin{array}{l}\text { - Analisados } 8 \text { artigos cuja média } \\
\text { de idade foi de um a } 11 \text { anos e } \\
\text { predominância do sexo masculino; } \\
\text { - Crianças menores de um ano } \\
\text { desenvolveram sintomas mais } \\
\text { graves; } \\
\text {-A maioria dos pacientes tinham } \\
\text { histórico de contato familiar; } \\
\text { - } 23 \% \text { tinham condição crônica } \\
\text { prévia, como doença pulmonar } \\
\text { crônica, doença cardíaca ou } \\
\text { supressão imunológica. }\end{array}$ & $\begin{array}{l}\cdot 10 \% \text { evoluem com pneumonia; } \\
\cdot 56 \% \text { tem febre, } 54 \% \text { tosse, } 13 \% \text { falta de } \\
\text { ar, faringite, dificuldade para se alimentar } \\
(11 \%) \text { rinorréia ( } 22 \%) \text {, gastroenterite e } \\
\text { vômito }(5 \%) .\end{array}$ & Não informado. \\
\hline $\begin{array}{l}\text { Armann, JP, } \\
\text { Diffloth N, Simon } \\
\text { A, Doenhardt M, } \\
\text { Hufnagel M, Trotter } \\
\text { A, Schneider D, } \\
\text { Hübner J, Berner R. } \\
2020^{(13)}\end{array}$ & $\begin{array}{l}\text { Obter dados sobre } \\
\text { hospitalização } \\
\text { de crianças e } \\
\text { adolescentes } \\
\text { com COVID-19 na } \\
\text { Alemanha, para fins } \\
\text { epidemiológicos } \\
\text { e melhor } \\
\text { compreensão da } \\
\text { doença nessa faixa } \\
\text { etária. }\end{array}$ & $\begin{array}{l}\text {-A transmissão: paciente índice } \\
\text { foi identificado em } 38 \% \text { dos } \\
\text { pacientes e em } 85 \% \text { desses casos } \\
\text { foi um dos familiares; } \\
-50 \% \text { do sexo masculino; } \\
-26 \% \text { tinham doenças pré- } \\
\text { existentes; } \\
\text { - Proporção de mortes (1:102). }\end{array}$ & $\begin{array}{l}\text { - Os sintomas clínicos: febre/sintomas } \\
\text { inespecíficos ( } 67 \%) \text {, infecção do trato } \\
\text { respiratório superior (41\%), bronquite/ } \\
\text { bronquiolite (16\%) e sintomas } \\
\text { gastrointestinais (17\%); } \\
\text { - As doenças subjacentes estavam } \\
\text { presentes em } 26 \% \text { dos pacientes, sendo } \\
50 \% \text { daqueles que receberam terapia } \\
\text { intensiva; } \\
\text { - Pneumonia, sepse ou achados clínicos } \\
\text { semelhantes, encefalite e síndrome do } \\
\text { desconforto respiratório agudo (SDRA) nos } \\
\text { pacientes graves; } \\
\text { - Uma coinfecção estava presente em } 10 \% \\
\text { dos casos: vírus sincicial respiratório, vírus } \\
\text { Epstein-Barr; } \\
\text { - Em } 17 \% \text { dos casos eram assintomáticos. }\end{array}$ & $\begin{array}{l}\text { - Dezesseis pacientes necessitaram de } \\
\text { terapia intensiva. } \\
\text { - Ventilação invasiva (5\%) e não invasiva } \\
\text { (7\%); } \\
\text { - Um único paciente recebeu } \\
\text { antibióticos para tratamento viral e } \\
\text { hidroxicloroquina; } \\
\text { - Suplementação de oxigênio (16\%); } \\
\text { - Traqueostomia (2\%); } \\
\text { - Inotrópicos/vasopressores (5\%); } \\
\text { - Inalação com broncodilatadores } \\
(17 \%) ; \\
\text { - Esteróides sistêmicos (9\%); } \\
\text { - Antibióticos (36\%); } \\
\text {-Tratamento antiviral para SARS-CoV-2 } \\
(1 \%) ; \\
\text { - Anti-reumático não esteróide (NSAR) } \\
\text { (22\%); } \\
\text {-Terapia de substituição renal (2\%). }\end{array}$ \\
\hline Patel NA. $2020^{(14)}$ & $\begin{array}{l}\text { Elucidar um melhor } \\
\text { entendimento do } \\
\text { impacto global } \\
\text { do COVID-19 } \\
\text { na população } \\
\text { pediátrica. }\end{array}$ & $\begin{array}{l}\text {-56\% eram do sexo masculino; } \\
\text { - Faixa etária foi de } 1 \text { dia a } 17 \\
\text { anos; } \\
\text { - } 21 \% \text { com comorbidades, as } \\
\text { mais comuns foram asma, } \\
\text { imunossupressão e doença } \\
\text { cardiovascular; } \\
\text { - Cerca de } 27,0 \% \text { dos pacientes } \\
\text { hospitalizados eram crianças } \\
\text { menores de } 1 \text { ano de idade; } \\
\text { - } 14,9 \% \text { assintomáticas; } \\
\text { - Exposição familiar ao CoviD-19 } \\
\text { ou viajem para área de contato } \\
(85,5 \%) \text { e propagação comunitária } \\
\text { (14,5\%); } \\
\text {-Taxa de morte: } 0.0018 \% .\end{array}$ & $\begin{array}{l}\text { · Tosse }(48 \%), \text { febre }(47 \%) \text {, dor de } \\
\text { garganta/faringite }(28,6 \%), \text { rinorreia, } \\
\text { espirros, congestão nasal }(13,7 \%), \\
\text { vômitos/náusea }(7,8 \%), \text { dor abdominal } \\
(6 \%) \text {, diarreia }(10,1 \%) \text {, dor de cabeça } \\
(24,3 \%) \text {, fadiga }(7,9 \%) \text {, mialgia }(22,7 \%) ; \\
\text { - Coinfecções por Influenza B (2 crianças), } \\
\text { Mycoplasma pneumonia (3 crianças), e } \\
\text { Enterobacter aerogenes (1 criança). }\end{array}$ & $\begin{array}{l}\text { - Interferon, antivirais e } \\
\text { hidroxicloroquina; } \\
\text { - Lopinavir-ritonavir foi o medicamento } \\
\text { mais utilizado; } \\
\text { - Uso de azitromicina ( } 1 \text { em cada } \\
\text { 4) e hidroxicloroquina ( } 3 \text { em cada } \\
\text { pacientes) e oseltamivir (3 em cada 4); } \\
\text { - Antibióticos. }\end{array}$ \\
\hline
\end{tabular}


Continuação.

\begin{tabular}{|c|c|c|c|c|}
\hline Autor/Ano & Objetivo & Epidemiologia & Manifestações clínicas & Medidas terapêuticas \\
\hline $\begin{array}{l}\text { White A, Mukherjee } \\
\text { P, Stremming } \\
\text { J, Sherlock LG, } \\
\text { Reynolds RM, } \\
\text { Smith D, et al., } \\
2020^{(15)}\end{array}$ & $\begin{array}{l}\text { Reportar uma } \\
\text { série de casos } \\
\text { em neonatos } \\
\text { com SARS-CoV-2, } \\
\text { adquirida por } \\
\text { transmissão } \\
\text { comunitária nos } \\
\text { EUA. }\end{array}$ & $\begin{array}{l}\text { - Três bebês com infecção } \\
\text { confirmada por SARS-CoV-2; } \\
\text { · Dois eram do sexo masculino; } \\
\text { · Todos nasceram a termo e } \\
\text { saudáveis; } \\
\text { - Um bebê nasceu por cesariana; } \\
\text { - Dois estavam em aleitamento } \\
\text { materno exclusivo na admissão; } \\
\text { · Dois bebês tiveram contato } \\
\text { com pessoas com sintomas } \\
\text { respiratórios e um não teve contato } \\
\text { mas consultou com pediatra. }\end{array}$ & $\begin{array}{l}\text { - Todos tiveram febre, rinorreia e hipóxia } \\
\text { leve com dessaturação no ar ambiente de } \\
80 \text { a } 90 \% \text {; } \\
\text { - } 0 \text { bebê mais jovem também apresentou } \\
\text { taquicardia, vasodilatação sistêmica e } \\
\text { conjuntivite bilateral e; } \\
\text { - Um paciente foi admitido com neutropenia } \\
\text { e os outros } 2 \text { se tornaram neutropênicos } \\
\text { durante a hospitalização. }\end{array}$ & $\begin{array}{l}\text { - Todos foram admitidos na UTIN; } \\
\text { - Os três bebês necessitaram de } \\
\text { oxigênio suplementar via cânula nasal } \\
\text { para manter a saturação de oxigênio } \\
>90 \% \text {. }\end{array}$ \\
\hline $\begin{array}{l}\text { Balasubramanian } \\
\text { S, Rao NM, Goenka } \\
\text { A, Roderick M, } \\
\text { Ramanan AV. } \\
2020^{(16)}\end{array}$ & $\begin{array}{l}\text { Dados sobre o } \\
\text { que sabemos e o } \\
\text { que não sabemos } \\
\text { sobre COVID-19 em } \\
\text { crianças. }\end{array}$ & $\begin{array}{l}\text {-90\% de todas as crianças são } \\
\text { assintomáticas, ou adquirem } \\
\text { infecção leve a moderada; } \\
\text { · Recuperação em 1-2 semanas; } \\
\text { · crianças têm prognóstico melhor } \\
\text { que adultos; } \\
\text { · período de incubação: } 2 \text { dias. }\end{array}$ & $\begin{array}{l}\text { - Febre }(50 \%) \text { e tosse }(38 \%) \text {; } \\
\text { - Outros sintomas: dor de garganta, } \\
\text { rinorréia, coriza, mialgia, fadiga, diarreia e } \\
\text { vômito. }\end{array}$ & $\begin{array}{l}\text { - Terapia de suporte com nutrição } \\
\text { adequada e ingestão de calorias, } \\
\text { controle de líquidos e eletrólitos e } \\
\text { suplementação de oxigênio; } \\
\text { - A comunicação com os pais e o alívio } \\
\text { da ansiedade é uma parte importante } \\
\text { da assistência; } \\
\text { - Tratamento sintomatológico; } \\
\text { - Antivirais e terapia imunomoduladora. }\end{array}$ \\
\hline $\begin{array}{l}\text { CDC COVID-19 } \\
\text { Response Team. } \\
2020^{(17)}\end{array}$ & $\begin{array}{l}\text { Avaliação preliminar } \\
\text { das características } \\
\text { do COVID-19 entre } \\
\text { crianças nos EUA. }\end{array}$ & $\begin{array}{l}\text { - Idade média: } 11 \text { anos; } \\
\text { - } 398 \text { crianças com menos de } 1 \\
\text { ano e } 291 \text { em crianças de } 1 \text { a } 4 \\
\text { anos; } \\
\text { - 57\% do sexo masculino; } \\
\text { - Exposição: } 9 \% \text { viagens e } 91 \% \\
\text { tiveram exposição familiar ou } \\
\text { comunitária; } \\
\text { - Crianças <1 ano representaram } \\
\text { o maior percentual de internação } \\
\text { hospitalar. }\end{array}$ & $\begin{array}{l}\text { - Febre, tosse e falta de ar ( } 73 \%) \text {, mialgia } \\
(23 \%) \text {, coriza }(7,2 \%) \text {, dor de garganta } \\
(24 \%) \text {, dor de cabeça ( } 28 \%) \text {, náusea e } \\
\text { vômito ( } 11 \%) \text {, dor abdominal }(5,8 \%) \text { e } \\
\text { diarreia ( } 13 \%) ; \\
\text { - As condições subjacentes mais comuns } \\
\text { foram doença pulmonar crônica, incluindo } \\
\text { asma ( } 40 \text { crianças), doença cardiovascular } \\
\text { ( } 25 \text { crianças) e imunossupressão (10 } \\
\text { crianças). }\end{array}$ & - Não informado \\
\hline $\begin{array}{l}\text { Choi SH, Kim HW, } \\
\text { Kang JM, Kim DH, } \\
\text { Cho EY. 2020 }\end{array}$ & $\begin{array}{l}\text { Resumir o } \\
\text { conhecimento atual } \\
\text { sobre o COVID-19 } \\
\text { em crianças e } \\
\text { adolescentes. }\end{array}$ & 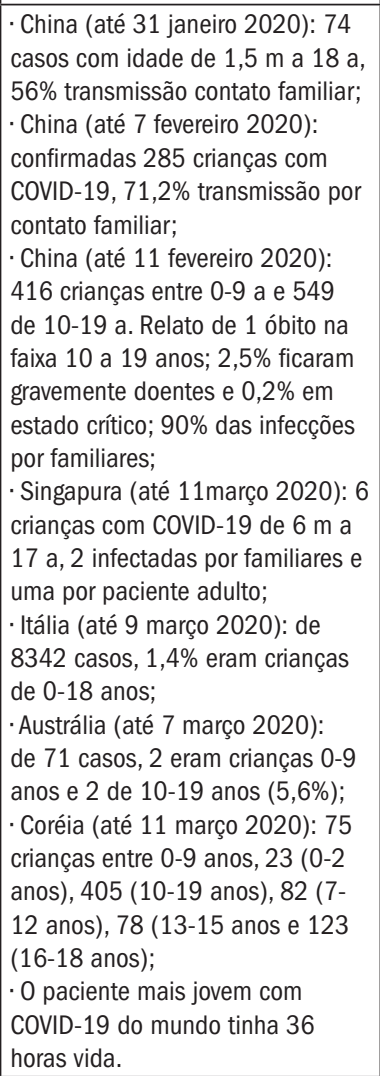 & $\begin{array}{l}\text { - Os sintomas mais comuns foram febre, } \\
\text { tosse, coriza, congestão nasal, dor de } \\
\text { garganta, dor de cabeça, vômito, diarreia; } \\
\text { - Relato pacientes assintomáticos; } \\
\text { - Pneumonia; } \\
\text { - Leucocitose e leucopenia, linfocitose e } \\
\text { linfopenia; } \\
\text { - Aumento da proteína C reativa e da } \\
\text { procalcitonina; } \\
\text { - Coinfecção por influenza A ou B vírus, } \\
\text { Mycoplasma pneumoniae, vírus sincicial } \\
\text { respiratório ou citomegalovírus. }\end{array}$ & $\begin{array}{l}\text { Um paciente, de } 3 \text { anos de idade, } \\
\text { recebeu tratamento intensivo com } \\
\text { oxigenoterapia. }\end{array}$ \\
\hline
\end{tabular}




\begin{tabular}{|c|c|c|c|c|}
\hline Autor/Ano & Objetivo & Epidemiologia & Manifestações clínicas & Medidas terapêuticas \\
\hline $\begin{array}{l}\text { De Rose DU, } \\
\text { Piersigilli F, } \\
\text { Ronchetti MP, } \\
\text { Santisi A, Bersani I, } \\
\text { Dotta A, Danhaive } \\
\text { 0, Auriti C. } 2020^{(19)}\end{array}$ & \begin{tabular}{|l|} 
Fornecer uma \\
visão geral do \\
conhecimento sobre \\
epidemiologia, \\
transmissão, SARS- \\
CoV-2, e apresentar \\
resultados em \\
recém-nascidos e \\
bebês até 6 meses \\
de vida.
\end{tabular} & $\begin{array}{l}\text { - As crianças são menos } \\
\text { susceptiveis a COVID-19 que os } \\
\text { adultos; } \\
\text { - Os } 5 \text { neonatos avaliados, tinham } \\
\text { idade de } 1 \text { mês e } 6 \text { dias a } 6 \\
\text { meses, } 3 \text { eram do sexo feminino e } \\
\text { nenhum foi a óbito. }\end{array}$ & $\begin{array}{l}\text { - Sintomas leves e inespecíficos, dentre } \\
\text { eles: hiporeatividade, tosse, congestão } \\
\text { nasal, recusa alimentar, diarreia e } \\
\text { distensão abdominal e aumento da } \\
\text { frequência respiratória; } \\
\text { - Os prematuros podem apresentar } \\
\text { letargia, desidratação e instabilidade da } \\
\text { temperatura; } \\
\text { · Leucopenia e linfocitopenia são } \\
\text { achados típicos; outros incluem } \\
\text { trombocitopenia leve e aumento da } \\
\text { creatina quinase, fosfatase alcalina, } \\
\text { alanina aminotransferase, aspartato } \\
\text { aminotransferase e lactato desidrogenase. }\end{array}$ & $\begin{array}{l}\text { - Uso de máscara durante a } \\
\text { amamentação e higiene das mãos; } \\
\text { - Neonatos com SARSCoV-2 devem ser } \\
\text { isolados e monitorados, sintomáticos ou } \\
\text { não, por pelo menos } 14 \text { dias, em quarto } \\
\text { com pressão negativa; } \\
\text {-Apoio psicológico aos pais; } \\
\text { - Monitoramento contínuo (frequência } \\
\text { cardíaca e respiratória, saturação de } \\
\text { oxigênio, temperatura, pressão arterial, } \\
\text { glicemia e sintomas gastrointestinais), } \\
\text { exames de sangue e Raio-x do tórax } \\
\text { devem ser realizados; } \\
\text { - Pode ser indicado uso surfactante, } \\
\text { imunoglobulina endovenosa, oxido nítrico, } \\
\text { oxigenioterapia por cânula nasal de alto } \\
\text { fluxo, ventilação mecânica não invasiva; } \\
\text {-Antibióticos devem ser prescritos apenas } \\
\text { para pacientes com infecção bacteriana } \\
\text { provável ou confirmada; } \\
\text {-Em neonatos gravemente enfermos, } \\
\text { pode ser necessária substituição renal } \\
\text { contínua (TRC) ou oxigenação por } \\
\text { membrana extracorpórea (ECMO). }\end{array}$ \\
\hline $\begin{array}{l}\text { Garazzino S, } \\
\text { Montagnani C, } \\
\text { Donà D, Meini A, } \\
\text { Felici E, Vergine G, } \\
\text { et al., } 2020^{(20)}\end{array}$ & $\begin{array}{l}\text { Relatar resultados } \\
\text { preliminares de } \\
\text { estudo multicêntrico } \\
\text { que investigou } \\
\text { os aspectos } \\
\text { epidemiológicos, } \\
\text { clínicos e } \\
\text { terapêuticos da } \\
\text { infecção por } \\
\text { SARS-CoV-2 em } \\
\text { lactentes, crianças e } \\
\text { adolescentes. }\end{array}$ & $\begin{array}{l}\text { - } 168 \text { casos pediátricos confirmados } \\
\text { em laboratório, com idade de } 1 \text { a } 17 \\
\text { a, média de } 5 \text { a, } 15 \text { neonatos; } \\
\text {-55,9\% do sexo masculino; } \\
\text {-67,9\% hospitalizados e } 19,6 \% \\
\text { apresentaram comorbidades (doenças } \\
\text { pulmonares crônicas, malformações, } \\
\text { câncer, epilepsia, síndrome genéticas } \\
\text { complexas, distúrbios gastrointestinais } \\
\text { e metabólicos); } \\
\text {-67,3\% das crianças tinham pelo } \\
\text { menos um dos pais com SARS-CoV-2. }\end{array}$ & $\begin{array}{l}\text { - Febre }(82 \%), \text { tosse }(48,8 \%), \text { rinite } \\
(26,8 \%) \text { vômitos e diarreia }(18,4 \%) ; \\
\text { - Proteina C reativa aumentada }(38,1 \%) ; \\
\text { leucopenia, linfopenia, neutropenia } \\
\text { presentes e Pneumonia intersticial } \\
(19,6 \%) ; \\
\text { - Coinfecção viral com rinovírus, vírus } \\
\text { Epstein-Barr, influenza; e coinfecção com } \\
\text { Streptococcus pneumoniae. }\end{array}$ & $\begin{array}{l}\text {-9,5\% recebeu oxigênio não invasivo; } 2 \text { RN } \\
\text { internados em UTIN; } \\
\text { ·Tratamentos experimentais para infecção } \\
\text { por SARS-CoV-2, incluindo lopinavir, } \\
\text { ritonavir, hidroxicloroquina e/ou azitromicina } \\
\text { e claritromicina foram administrados a } 49 \\
\text { crianças; } \\
\text { · Esteróide sistêmico foi administrado } \\
\text { apenas em um caso; } \\
\text {-Tratamentos antivirais foram } \\
\text { preferencialmente administrados a crianças } \\
\text { que estavam mais gravemente doentes. }\end{array}$ \\
\hline $\begin{array}{l}\text { Aghdam MK, Jafari } \\
\text { N, Eftekhari K. } \\
2020^{(21)}\end{array}$ & $\begin{array}{l}\text { Relatar o caso } \\
\text { de um RN com } \\
\text { COVID-19 e } \\
\text { informar sobre a } \\
\text { probabilidade de } \\
\text { bebês apresentarem } \\
\text { manifestações } \\
\text { clínicas } \\
\text { inespecíficas da } \\
\text { doença. }\end{array}$ & $\begin{array}{l}\text { - RN a termo com } 15 \text { dias vida, } \\
\text { parto cesariano; } \\
\text { - Pais apresentando sintomas } \\
\text { de COVID-19, mas não foram } \\
\text { testados; } \\
\text { - Alta em } 6 \text { dias e em boas } \\
\text { condições. }\end{array}$ & $\begin{array}{l}\text { - Febre, letargia e manchas cutâneas, } \\
\text { taquipneia, retração subcostal leve; PCR } \\
\text { positivo para COVID-19. }\end{array}$ & $\begin{array}{l}\text { · Isolamento na UTI Neonatal; } \\
\text { - Fluidoterapia; } \\
\text { - Oxigenoterapia; } \\
\text { - Uso de antibioticoterapia com } \\
\text { vancomicina e Amicacina e antiviral } \\
\text { Oseltamivir. }\end{array}$ \\
\hline $\begin{array}{l}\text { Panahi L, Amiri M, } \\
\text { Pouy S. 2020(22) }\end{array}$ & $\begin{array}{l}\text { Revisar artigos } \\
\text { publicados sobre } \\
\text { manifestações } \\
\text { clínicas e } \\
\text { características de } \\
\text { crianças e bebês } \\
\text { com COVID-19. }\end{array}$ & $\begin{array}{l}\text { - } 2228 \text { crianças com idade entre } 1 \text { dia } \\
\text { a } 16 \text { anos; } \\
\text { · } 740 \text { crianças confirmaram COVID-19; } \\
\text { - Duração média da infecção de } 1 \text { a } \\
42 \text { dias, melhora relatada de } 1 \text { a } 2 \\
\text { semanas; } \\
\text { - } 99,72 \% \text { receberam alta hospitalar; } \\
\text { - } 2 \text { óbitos, um de RN prematuro e } \\
\text { baixo peso e outro de uma criança de } \\
14 \text { anos; } \\
\text { - } 3 \text { casos com amostras de fezes } \\
\text { positivo - transmissão fecal-oral deve } \\
\text { ser considerada em crianças; } \\
\text { - Transmissão por contatos familiares } \\
\text { ou próximos; } \\
\text { - Crianças mais jovens, com doenças } \\
\text { subjacentes e imunodeficiência } \\
\text { apresentam maior risco de infecção } \\
\text { grave. }\end{array}$ & $\begin{array}{l}\text { - } 92 \% \text { das crianças foram assintomáticas } \\
\text { ou com sintomas como febre }(96 \%) \text {, tosse } \\
\text { seca }(91 \%) \text {, fadiga }(45 \%) \text {, sintomas leves } \\
\text { do trato respiratório superior ( } 66 \%) \text {, dor } \\
\text { abdominal }(23 \%) \text {, náuseas e vomito (12\%) } \\
\text { e diarreia ( } 7 \%) ; \\
\text {-A gravidade da doença foi relatada como } \\
\text { leve em } 72 \% \text { dos casos, moderado em } \\
22 \% \text { e grave em } 6 \% \text { das crianças; } \\
\text { - Complicações mais comuns: dispneia ou } \\
\text { hipóxia, insuficiência respiratória aguda, } \\
\text { SDRA e falência de múltiplos órgãos. }\end{array}$ & · Não informado \\
\hline
\end{tabular}


Continuação.

\begin{tabular}{|c|c|c|c|c|}
\hline Autor/Ano & Objetivo & Epidemiologia & Manifestações clínicas & Medidas terapêuticas \\
\hline $\begin{array}{l}\text { Sun D, Chen X, Li } \\
\text { H, Lu XX, Xiao H, } \\
\text { Zhang FR, Liu ZS. } \\
2020^{(23)}\end{array}$ & $\begin{array}{l}\text { Descrever as } \\
\text { características } \\
\text { clínicas e } \\
\text { laboratoriais de } \\
\text { lactentes com } \\
\text { menos de } 1 \text { ano de } \\
\text { idade (excluindo } \\
\text { recém-nascidos) } \\
\text { com COVID-19. }\end{array}$ & \begin{tabular}{|l|} 
- 36 pacientes, com idade média \\
de 6,4 meses; \\
- $61 \%$ do sexo masculino; \\
- $86 \%$ foram infectados por \\
familiares; \\
- 0 tempo médio entre o início \\
dos sintomas até a alta foi de 7 \\
a 36 dias (média 16,8 dias); \\
- 33 lactentes foram \\
classificados como tipo comum, \\
dois como grave e uma infecção \\
assintomática; \\
-97,22\% das crianças \\
recuperaram, e ocorreu um óbito.
\end{tabular} & $\begin{array}{l}\text { - Tosse }(77,78 \%) \text {, febre }(47,42 \%), \\
\text { diarreia }(22,22 \%), \text { congestão/secreção } \\
\text { nasal }(16,67 \%), \text { náusea/vômito } \\
(11,11 \%), \text { constipação }(2,78 \%) ; \\
\cdot 61 \% \text { das crianças desenvolveram } \\
\text { pneumonia bilateral e } 36,1 \% \text { pneumonia } \\
\text { unilateral; } \\
\cdot 47,22 \% \text { teve complicações (lesões } \\
\text { miocárdicas, função hepática anormal e } \\
\text { hipogamaglobulinemia); } \\
\cdot 25 \% \text { dos lactentes apresentavam } \\
\text { doenças subjacentes, incluindo eczema, } \\
\text { obstrução do saco lacrimal, eritema } \\
\text { multiforme, pneumonia (infecção } \\
\text { por influenza A e micoplasma), } \\
\text { hipotireoidismo, defeito septo } \\
\text { atrial, fenda palatina e hemorragia } \\
\text { intracraniana traumática. }\end{array}$ & $\begin{array}{l}\cdot 97,22 \% \text { das crianças receberam } \\
\text { agentes antivirais (interferon, virazol) } \\
\text { administrados principalmente por } \\
\text { inalação; } \\
\text { - } 63,89 \% \text { dos pacientes foram } \\
\text { tratados com medicina tradicional } \\
\text { chinesa (incluindo fitoterapia, } \\
\text { acupuntura e massagem); } \\
\cdot \text {-41,67\% dos pacientes receberam } \\
\text { antibióticos (cefmetazol, } \\
\text { azitromicina); } \\
\text { - Tratamento com sintomáticos para } \\
\text { as complicações; } \\
\text { - Apenas três bebês receberam } \\
\text { oxigenoterapia }(8,33 \%) .\end{array}$ \\
\hline $\begin{array}{l}\text { Wang J, Wang D, } \\
\text { Chen GC, Tao XW, } \\
\text { Zeng LK. } 2020^{(24)}\end{array}$ & $\begin{array}{l}\text { A partir do } \\
\text { relato de um } \\
\text { caso, melhorar } \\
\text { a compreensão } \\
\text { da infecção por } \\
\text { SARS-CoV-2 em } \\
\text { neonatos. }\end{array}$ & $\begin{array}{l}\text { - Neonato, sexo masculino, } 19 \\
\text { dias, idade gestacional 38+6 } \\
\text { semanas; } \\
\text { - período de hospitalização: } 14 \\
\text { dias; } \\
\text { - Pais testaram positivo para } \\
\text { SARS-CoV-2; } \\
\text { - Alta após } 14 \text { dias. }\end{array}$ & $\begin{array}{l}\text { - Sintomas iniciais gastrointestinais } \\
\text { como vômito, recusa do leite materno, } \\
\text { diarreia, na evolução houve febre } 37,7 \text { - } \\
39^{\circ} \mathrm{C} \text { e tosse. }\end{array}$ & $\begin{array}{l}\text { - } 0 \text { paciente foi colocado em } \\
\text { quarentena em unidade de } \\
\text { isolamento neonatal; } \\
\text { - Tratamento sintomático, como spray } \\
\text { nasal e reposição de fluidos com } \\
\text { interferon. }\end{array}$ \\
\hline $\begin{array}{l}\text { Xia W, Shao J, } \\
\text { Guo Y, Peng X, Li } \\
\text { Z, Hu D. } 2020^{(25)}\end{array}$ & $\begin{array}{l}\text { Discutir as } \\
\text { diferentes } \\
\text { características } \\
\text { clínicas, } \\
\text { laboratoriais } \\
\text { e tomografia } \\
\text { computadorizada } \\
\text { (TC) em pacientes } \\
\text { pediátricos e } \\
\text { adultos com novo } \\
\text { coronavírus de } \\
\text { 2019. }\end{array}$ & $\begin{array}{l}\text { - Maioria do sexo masculino; } \\
1 \text { dia a } 14 \text { anos; } \\
\text {-13 pacientes com histórico de } \\
\text { contato próximo com familiares } \\
\text { diagnosticados com COVID - 19; } \\
\text { - } 20 \text { pacientes com histórico } \\
\text { prévio de doenças congênitas ou } \\
\text { adquiridas; } \\
\cdot \text { Coinfecção com outros } \\
\text { patógenos, incluindo vírus } \\
\text { influenza A e B, micoplasma, } \\
\text { vírus sincicial respiratório e } \\
\text { citomegalovírus; } \\
\text { - Tempo médio de hospitalização } \\
\text { de } 12,9 \text { dias. }\end{array}$ & $\begin{array}{l}\cdot \text { Febre acima } 37.3^{\circ} \mathrm{C} \text { em } 12 \text { casos } \\
(12 / 20,60 \%) \text {, tosse em } 13 \text { casos } \\
(13 / 20,65 \%) \text {, diarreia em } 3 \text { cases } \\
(3 / 20,15 \%) \text {, coriza em } 3 \text { cases }(3 / 20 \text {, } \\
15 \%) \text {, dor de garganta em } 1 \text { case } \\
(1 / 20,5 \%) \text {, vômito em } 2 \text { casos }(2 / 20 \text {, } \\
10 \%) \text {,taquipneia em } 2 \text { casos }(2 / 20, \\
10 \%), \text { e fadiga em } 1 \text { case }(1 / 20,5 \%) \text {; } \\
\cdot \text { TC tórax: Imagem pulmonar com lesões } \\
\text { bilateriais e lesões subpleurais em } \\
\text { todos os casos; consolidação com sinal } \\
\text { de halo em } 50 \% \text { e opacidade de vido } \\
\text { opaco em } 60 \% \text {. }\end{array}$ & $\begin{array}{l}\text { - Todos os pacientes foram tratados } \\
\text { na enfermaria de isolamento. }\end{array}$ \\
\hline $\begin{array}{l}\text { Xiong } \sqcup \text {, Zhou MY, } \\
\text { He XQ, Wu Y, Xie } \\
\text { XL. 2020(26) }\end{array}$ & $\begin{array}{l}\text { Relacionar o papel } \\
\text { do COVID-19 } \\
\text { em pacientes } \\
\text { pediátricos com } \\
\text { gastroenterite. } \\
\end{array}$ & \begin{tabular}{|l|} 
- Transmissão pessoa-pessoa \\
por meio de contato próximo, \\
incluindo gotículas e transmissão \\
de contato.
\end{tabular} & $\begin{array}{l}\text { Os sintomas mais comuns foram febre, } \\
\text { vômito, diarreia, tosse seca e falta de ar. }\end{array}$ & - Não informado \\
\hline $\begin{array}{l}\text { Zeng LK, Tao XW, } \\
\text { Yuan WH, Wang } \\
\text { J, Liu X, Liu ZS. } \\
2020^{(27)}\end{array}$ & $\begin{array}{l}\text { Descrever o } \\
\text { primeiro caso de } \\
\text { neonato acometido } \\
\text { pelo COVID-19. }\end{array}$ & $\begin{array}{l}\text { - Neonato do sexo masculino, } 17 \\
\text { dias de idade, idade gestacional } \\
\text { foi de } 39 \text { semanas; } \\
\text { - Pais diagnosticados com } \\
\text { COVID-19. }\end{array}$ & $\begin{array}{l}\text { - Sintomas: espirros e regurgitação de } \\
\text { leite materno, febre transitória, vômito } \\
\text { e diarreia; } \\
\text { - Linfócitos aumentados; } \\
\text { - Percebidas pequenas faixas de sombras } \\
\text { borradas nos dois campos pulmonares. }\end{array}$ & $\begin{array}{l}\text { - Criança internada no isolamento } \\
\text { neonatal em incubadora; redução de } \\
\text { manipulação pela equipe; } \\
\text { - Observação constante no } \\
\text { isolamento; } \\
\text { - Monitorização da frequência } \\
\text { cardíaca e respiratória, pressão } \\
\text { arterial, glicose no sangue; } \\
\text { - Atenção quanto as precauções } \\
\text { durante a alimentação, limpeza da } \\
\text { cavidade oral, troca de fraldas ou } \\
\text { outro momento de contato físico; } \\
\text { - Cuidados com a higiene das mãos, } \\
\text { desinfecção eficaz dos aparelhos de } \\
\text { enfermagem após o uso. }\end{array}$ \\
\hline
\end{tabular}

Continua... 


\begin{tabular}{|c|c|c|c|c|}
\hline Autor/Ano & Objetivo & Epidemiologia & Manifestações clínicas & Medidas terapêuticas \\
\hline $\begin{array}{l}\text { Zhang, C., Gu, J., } \\
\text { Chen, Q., Deng, } \\
\text { N., Li, J., Huang, L., } \\
\text { Zhou, X. 2020(28) }\end{array}$ & $\begin{array}{l}\text { Descrever } \\
\text { características do } \\
\text { quadro clínico e } \\
\text { epidemiológico } \\
\text { dos pacientes } \\
\text { pediátricos } \\
\text { para fornecer } \\
\text { informações } \\
\text { valiosas sobre o } \\
\text { diagnóstico precoce } \\
\text { e avaliação do } \\
\text { COVID-19 em } \\
\text { crianças. }\end{array}$ & $\begin{array}{l}\text {-34 pacientes pediátricos com } \\
\text { COVID-19 com idade entre } 1 \mathrm{~m} \\
\text { a } 12 \mathrm{a} \text {; } \\
\text { - } 18 \text { pacientes tiveram contato } \\
\text { com outras moradores de Wuhan; } \\
13 \text { tiveram contato próximo com } \\
\text { pessoas da família infectadas } \\
\text { com o vírus e } 16 \text { não tinham } \\
\text { tido exposição a uma fonte } \\
\text { identificada; } \\
\text {-A duração média de internação } \\
\text { foi de } 10 \text { dias para todos os } \\
\text { pacientes. }\end{array}$ & $\begin{array}{l}\text {-Sintomas iniciais: febre e tosse, seguido } \\
\text { de expectoração, taquipneia, vômito e } \\
\text { diarreia; } \\
\text { - Todos os pacientes do presente estudo } \\
\text { apresentaram formas leves (18\%) ou } \\
\text { moderadas (82\%) de COVID-19; } \\
\text { - Infecções mistas de outros patógenos } \\
\text { respiratórios como M. pneumoniae, vírus } \\
\text { influenza B, vírus influenza A, vírus sincicial, } \\
\text { vírus Epstein-Barr, vírus parainfluenza e } \\
\text { adenovírus foram relatados; } \\
\text { - } 6 \text { pacientes apresentaram comorbidades; } \\
\text {-TC de tórax: lesões irregulares nos } \\
\text { lóbulos, opacidades em vidro fosco foram } \\
\text { detectadas. }\end{array}$ & $\begin{array}{l}\text { - Tratamentos antivirais foram } \\
\text { empregados de acordo com a } \\
\text { recomendação para casos leves e } \\
\text { moderados; } \\
\text { - Todos os pacientes receberam } \\
\text { nebulização por interferon- } \alpha \text { duas vezes } \\
\text { ao dia; } \\
\text { - Ribavirina foi administrado a } 15 \\
\text { pacientes duas vezes ao dia; } \\
\text { - tratamento com antiviral interferon } \\
\text { via nebulização e Ribavirin duas vezes } \\
\text { ao dia; } \\
\text { - } 20 \text { pacientes receberam tratamento } \\
\text { tradicional da medicina chinesa em } \\
\text { adição ao antiviral; } \\
\text {-Antibióticos foram administrados a } 11 \\
\text { pacientes com diagnóstico inicial de } \\
\text { infecção bacteriana e foram retirados } \\
\text { após confirmação do CoviD-19; } \\
\text { - } 9 \text { pacientes receberam } \\
\text { antibioticoterapia devido a } \\
\text { preocupações com infecções mistas } \\
\text { durante a hospitalização; } \\
\text {-A azitromicina foi administrada a } 9 \\
\text { pacientes com pneumonia; } \\
\text { ·Corticosteróide e oxigenioterapia } \\
\text { também foram empregados. }\end{array}$ \\
\hline $\begin{array}{l}\text { Zhou Y, Yang GD, } \\
\text { Feng K, Huang H, } \\
\text { Yun YX, Mou XY, } \\
\text { Wang LF. 2020 }\end{array}$ & $\begin{array}{l}\text { Estudar as } \\
\text { características } \\
\text { clínicas e os } \\
\text { achados da } \\
\text { tomografia } \\
\text { computadorizada do } \\
\text { tórax da doença de } \\
\text { coronavírus } 2019 \\
\text { (COVID-19) em } \\
\text { bebês e crianças } \\
\text { pequenas. }\end{array}$ & $\begin{array}{l}\text { - Idades entre } 7 \text { meses e } 3 \text { anos; } \\
\text { - Das } 9 \text { crianças, } 4 \text { eram do sexo } \\
\text { masculino e } 5 \text { do feminino; } \\
\text { - } 3 \text { pacientes têm histórico } \\
\text { de viagens em Hubei e todas } \\
\text { as crianças têm familiares } \\
\text { diagnosticados com COVID-19. }\end{array}$ & $\begin{array}{l}\text { - Sintomas: febre, tosse, coriza; } \\
\text { - A contagem de glóbulos brancos e } \\
\text { linfócitos estava aumentada; } \\
\text { - Sinais de inflamação pulmonar, derrame } \\
\text { pleural, opacidades em vidro fosco e o } \\
\text { "sinal de halo"; } \\
\text { - } 0 \text { aspartato aminotransferase, alanina } \\
\text { aminotransferase, lactato desidrogenase e } \\
\text { Proteína C-Reativa estavam elevados. }\end{array}$ & $\begin{array}{l}\text {-Todas as crianças estavam no } \\
\text { isolamento hospitalar; } \\
\text { - Realizada inalação de interferon; } \\
\text { - } 6 \text { crianças receberam tratamento oral } \\
\text { com lopinavir e ritonavir. }\end{array}$ \\
\hline
\end{tabular}

\section{Discussão}

Evidenciou-se que as publicações sobre a infecção por COVID-19 em crianças menores de 5 anos já são em número considerável, mas a maioria são estudos de revisão. Embora predominem estudos originários da China, primeiro país a identificar a doença, percebe-se que pesquisadores de diversos países e continentes estão empenhados na busca de respostas sobre essa nova doença, no intuito de produzir conhecimentos para tratar e preveni-la. Observou-se a ausência de estudos publicados no Brasil, até a data da revisão. Ainda, a maioria dos estudos primários analisados dedicou-se a estudar os prontuários das crianças hospitalizadas para descrever as manifestações clínicas e identificar os tratamentos utilizados, uma vez que a doença é nova e não existe ainda tratamento específico.
O conhecimento que se tem até o momento sobre a COVID- 19 mostra que a doença afeta indivíduos de todas as faixas de idade, inclusive recém-nascidos, entre esses aqueles nascidos prematuramente, o que foi descrito em outros estudos. ${ }^{(30,31)}$ Com relação aos $\mathrm{RN}$, ainda são poucas as informações sobre as apresentações clínicas da COVID-19. A revisão mostrou que apesar das manifestações da doença serem menos graves nas crianças do que nos pacientes adultos, os lactentes menores de um ano apresentam complicações mais graves do que as crianças mais velhas. ${ }^{(10,13,14,16,18,20-22)}$ Nesse sentido, os RN merecem atenção especial, visto que seu sistema imunológico ainda é imaturo, tornando-os mais suscetíveis à infecção pelo vírus.

Quanto às manifestações clínicas nos neonatos prematuros, produção analisada nesta revisão afirma 
que estas podem ser inespecíficas, e incluem síndrome do desconforto respiratório agudo, instabilidade térmica e gastrointestinal e disfunção cardiovascular. ${ }^{(19)}$

Em relação aos recém-nascidos, ainda persiste a incerteza quanto à transmissão vertical do vírus, ou seja, a passagem do vírus da mãe para o bebê antes e após o nascimento. Incerteza essa mencionada por estudo analisado nesta revisão. ${ }^{(19)}$ Autores defendem que não ocorre a transmissão vertical em gestantes contaminadas pelo COVID-19, porque durante o pico de infecção não há tempo hábil para a produção materna de anticorpos e a imunidade passiva se desenvolver, e portanto, o feto não entra em contato com a doença. ${ }^{(32)}$ Acredita-se que a transmissão do vírus para o RN ocorra, principalmente, através de gotículas respiratórias por meio de contato próximo com pessoas infectadas (mãe, familiares, cuidadores e visitantes), além de adquirir infecções em hospitais e em locais públicos. ${ }^{(33)}$ Os estudos analisados descreveram que a contaminação do vírus nas crianças ocorreu com maior incidência pela transmissão familiar, seguida da comunitária. ${ }^{(10-13,15-17,20-23)}$ Um dos estudos relatou a presença do vírus nas fezes, aventando a possibilidade de transmissão fecal-oral em crianças. ${ }^{(22)}$

Um elemento considerável na configuração do perfil epidemiológico de crianças com COVID-19 é a presença de doenças ou condições pré-existentes. Estas podem ser tomadas como fatores de risco para o agravamento da infecção na população em geral, nas crianças esse comportamento também tem sido observado, inclusive com óbito naquelas acometidas pelo vírus, segundo pesquisa analisada nessa revisão. ${ }^{(18)}$ Pesquisadores apontam que determinadas doenças, principalmente as do sistema cardiovascular e sistema imunológico, são as principais responsáveis pelo agravamento da infecção no público adulto. ${ }^{(34)}$ No que concerne às crianças e adolescentes, embora nos estudos analisados as crianças apresentassem comorbidades, a OMS ressalta que ainda são incipientes as evidências sobre as comorbidades reputadas como fatores de risco para o agravamento dos casos. ${ }^{(35)}$

Na presente revisão, encontrou-se como doença ou condição pré-existente a presença de problemas respiratórios, inclusive a asma, problemas cardíacos, câncer, fibrose cística, epilepsia, situações de imunossupressão, prematuridade, broncodisplasia, síndrome nefrótica, ${ }^{(10,13,19,21,24)}$ dentre outras.
A maior parte dos estudos analisados mencionou a necessidade de hospitalização para tratamento da doença, em especial entre os menores de um ano de idade. Pesquisa evidenciou que apesar das manifestações leves ou moderadas, em alguns casos, a criança pode necessitar de hospitalização e demandar cuidados intensivos. ${ }^{(35)}$ Quanto a necessidade de cuidados intensivos, com exceção dos estudos ${ }^{(14,20)}$ que relataram a internação dos neonatos em UTIN, outros quatro estudos citaram internação das crianças em UTI pediátrica. ${ }^{(10,12,17,19)}$

$\mathrm{Na}$ presente revisão, febre, tosse e diarreia foram as manifestações clínicas mais citadas pelos artigos. Dentre os artigos analisados, revisão sistemática apontou tosse, febre e dor de garganta/faringite, como os sintomas mais comuns, além de $14,9 \%$ das crianças positivas para infecção por SARS-CoV-2 serem assintomáticos. ${ }^{(13)}$ Investigação com oito crianças e adolescentes com COVID-19 internados na Unidade de Terapia Intensiva em Wuhan, na China evidenciou que todas apresentaram dispneia, seguida de febre, sendo que seis dos pacientes analisados tiveram tosse. ${ }^{(36)} \mathrm{Ou}-$ tra pesquisa também mostrou que as características clinicas prevalentes foram a tosse $(48,5 \%)$, eritema faríngeo $(46,2 \%)$ e a febre $(41,5 \%) .{ }^{(37)}$

Aparentemente, em crianças que desenvolveram sinais e sintomas da COVID-19, esses foram semelhantes aos apresentados por adultos. Todavia, estudo evidenciou que entre os adultos e idosos, a dispneia é mais comum do que sintomas gastrintestinais, como diarreia, tida como uma manifestação pouco referenciada entre adultos com a doença. ${ }^{(38)}$

No que diz respeito as medidas terapêuticas descritas nos estudos analisados, apesar de não se ter tratamento consensual para a COVID-19, observa-se que as medidas são de suporte com nutrição adequada e ingestão de calorias, controle de líquidos e eletrólitos e suplementação de oxigênio, de acordo com a necessidade da criança. ${ }^{(12,14-15,17-20)}$ Ressalta-se que um dos estudos relatou a utilização da medicina chinesa tradicional (acupuntura, fitoterapia e massagens) no tratamento das crianças. ${ }^{(22)}$

Quanto a terapêutica medicamentosa, semelhantemente ao observado na população adulta, as crianças também receberam antivirais, antibióticos, bem como os medicamentos experimentais para o SARS-CoV-2, como a hidroxicloroquina. . $10,12-14,19,20,27,28)^{U} \mathrm{~m}$ dos estudos 
analisados recomenda a terapia substitutiva renal continua (TRC) ou a oxigenação por membrana extracorpórea $(\mathrm{ECMO})$ em neonatos gravemente doentes. ${ }^{(17)}$

Precauções mais gerais forem descritas em pesquisa que analisou o primeiro caso de neonato acometido pela COVID-19, na China, entre elas, precauções durante a alimentação, limpeza da cavidade oral, troca de fraldas ou outro momento de contato físico com o RN e cuidados gerais implementados pela equipe de enfermagem, higiene das mãos, desinfecção eficaz dos aparelhos após o uso. ${ }^{(26)}$

Embora tenhamos utilizado a palavra-chave cuidados de enfermagem, não houve retorno de referências que abordassem o assunto. Assim, destaca-se a importância da divulgação da atuação da enfermagem nessas ações, não apenas em razão de sua capacidade técnica, mas também por possuir o maior número de profissionais da área da saúde, e ser a única categoria profissional que está junto ao paciente durante as 24 horas do dia ${ }^{(39)}$ em especial, no cuidado aos neonatos, pacientes totalmente dependente dos cuidados da equipe de enfermagem e susceptíveis a infecção pelo vírus.

\section{Conclusão}

Essa revisão identificou um número expressivo de artigos publicados sobre o COVID-19 em população pediátrica, sendo a maior parte desenvolvida na China seguido pelos EUA; com predomínio de revisão da literatura e estudos de casos, trazendo informações que contribuem para o conhecimento acerca da epidemiologia, manifestações clínicas e tratamento da doença SARS-CoV-2. Não foram encontradas publicações nacionais e nem referentes aos cuidados de enfermagem no manejo das crianças durante a hospitalização, revelando-se uma lacuna. Assim, torna-se necessário o investimento em pesquisas sobre o tema com enfoque nos cuidados de enfermagem envolvendo a população pediátrica brasileira. Houve predomínio de crianças do sexo masculino, menores de um ano, incluindo-se RN, em transmissão familiar, seguida da comunitária. Baixo número de internação em UTI, assim como de óbitos. As manifestações clínicas mais frequentes foram febre, tosse seca, falta de ar/dispneia, com sintomas moderados, podendo haver acometimento de coinfecção por outros vírus, incluindo adenovírus e vírus sincicial respiratório. Dentre as medidas terapêuticas pode-se verificar a utilização de isolamento hospitalar, tratamento experimental, com o uso de antivirais e antibióticos, além de tratamento de suporte, com monitoramento contínuo, fluidoterapia, oxigenoterapia inalatória e ventilação não invasiva.

\section{Referências}

1. World Health Organization (WHO). Clinical management of severe acute respiratory infection (SARI) when COVID-19 disease is suspected. Genève: WHO; 2020 [updated 2020 Jul 20; cited 2020 Sep 23]. Available from: https://www.who.int/publications/i/item/ clinical-management-of-COVID-19

2. Coronaviridae Study Group of the International Committee on Taxonomy of Viruses. The species Severe acute respiratory syndrome-related coronavirus: classifying 2019-nCoV and naming it SARS-CoV-2. Nat Microbiol. 2020;5(4):536-44.

3. Ren LL, Wang YM, Wu ZQ, Xiang ZC, Guo L, Xu T, et al. Identification of a novel coronavirus causing severe pneumonia in human: a descriptive study. Chin Med J (Engl). 2020;133(9):1015-24.

4. Epidemiology Working Group for NCIP Epidemic Response, Chinese Center for Disease Control and Prevention. [The epidemiological characteristics of an outbreak of 2019 novel coronavirus diseases (COVID-19) in China]. Zhonghua Liu Xing Bing Xue Za Zhi. 2020;41(2):145-51. Chinese.

5. Jiehao C, Jin X, Daojiong L, Zhi Y, Lei X, Zhenghai Q, et al. A case series of children with 2019 novel coronavirus infection: clinical and epidemiological features. Clin Infect Dis. 2020;71(6):1547-51.

6. Coronavírus: 0 mapa que mostra 0 alcance mundial da doença. BBC News; 2020 [atualizado 2020 Ago; citado 2020 Set 15]. Disponível em: https://www.bbc.com/ portuguese/brasil-52472202

7. Coronavirus disease. 2019 (COVID-19). The right clinical information, right where it's needed. BMJ Best Practice; 2020 [last updated May 01, 2020; cited 2020 Sep 23]. Available from: https://bestpractice.bmj.com/topics/en-us/3000168/pdf/3000168/ Coronavirus\%20disease\%202019\%20\%28COVID-19\%29.pdf

8. Rasmussen SA, Thompson LA. Coronavirus Disease 2019 and children: what pediatric health care clinicians need to know. JAMA Pediatr. 2020;174(8):743-4.

9. Safadi MA. The intriguing features of COVID-19 in children and its impact on the pandemic. J Pediatr (Rio J). 2020;96(3):265-8.

10. Zheng F, Liao C, Fan QH, Chen HB, Zhao XG, Xie ZG, et al. Clinical characteristics of children with coronavirus disease 2019 in Hubei, China. Curr Med Sci. 2020;40(2):275-80.

11. Sousa LM, Marques-Vieira CM, Severino SS, Antunes AV. Metodologia de revisão integrativa da literatura em enfermagem. Rev Invest Enferm. 2017;2(21):17-26.

12. Bal ZŞ, Kurugöl Z, Özkınay F. Clinical features of COVID-19 in children. J Pediatr Res. 2020;2(7):88-91.

13. Armann JP, Diffloth N, Simon A, Doenhardt M, Hufnagel M, Trotter A, et al. Hospital admission in children and adolescents with COVID-19-early results from a national survey conducted by the German Society for Pediatric Infectious Diseases (DGPI). Dtsch Arztebl Int. 2020;117(21):373-4.

14. Patel NA. Pediatric COVID-19: systematic review of the literature. Am J Otolaryngol. 2020;41(5):102573.

15. White A, Mukherjee P, Stremming J, Sherlock LG, Reynolds RM, Smith D, et al. Neonates hospitalized with community-acquired SARS-CoV-2 in a Colorado neonatal intensive care unit. Neonatology. 2020;4:1-5.

17. Balasubramanian S, Rao NM, Goenka A, Roderick M, Ramanan AV. Coronavirus disease 2019 (COVID-19) in children - what we know so far and what we do not. Indian Pediatr. 2020;57(5):435-42.

17. Bialek S, Gierke R, Hughes M, McNamara LA, Pilishvili T, Skoff T; CDC COVID-19 Response Team. Coronavirus Disease 2019 in Children - United States, February 12-April 2, 2020. MMWR Morb Mortal Wkly Rep. 2020;69(14):422-6.

18. Choi SH, Kim HW, Kang JM, Kim DH, Cho EY. Epidemiology and clinical features of coronavirus disease 2019 in children. Clin Exp Pediatr. 2020;63(4):125-32. 
19. De Rose DU, Piersigilli F, Ronchetti MP, Santisi A, Bersani I, Dotta A, et al.; Study Group of Neonatal Infectious Diseases of The Italian Society of Neonatology (SIN). Novel Coronavirus disease (COVID-19) in newborns and infants: what we know so far. Ital J Pediatr. 2020;46(1):56.

20. Garazzino S, Montagnani C, Donà D, Meini A, Felici E, Vergine G, et al.; Italian SITIP-SIP Pediatric Infection Study Group; Italian SITIP-SIP SARS-CoV-2 paediatric infection study group*. Multicentre Italian study of SARS-CoV-2 infection in children and adolescents, preliminary data as at 10 April 2020. Euro Surveill. 2020;25(18):2000600.

21. Kamali Aghdam M, Jafari N, Eftekhari K. Novel coronavirus in a 15-day-old neonate with clinical signs of sepsis, a case report. Infect Dis (Lond). 2020;52(6):427-9.

22. Panahi L, Amiri M, Pouy S. Clinical characteristics of COVID-19 infection in newborns and pediatrics: a systematic review. Arch Acad Emerg Med. 2020;8(1):e50.

23. Sun D, Chen X, Li H, Lu XX, Xiao H, Zhang FR, et al. SARS-COV-2 infection in infants under 1 year of age in Wuhan City, China. World J Pediatr. 2020;16(3):260-6.

24. Wang J, Wang D, Chen GC, Tao XW, Zeng LK. [SARS-CoV-2 infection with gastrointestinal symptoms as the first manifestation in a neonate]. Zhongguo Dang Dai Er Ke Za Zhi. 2020;22(3):211-4. Chinese.

25. Xia W, Shao J, Guo Y, Peng X, Li Z, Hu D. Clinical and CT features in pediatric patients with COVID-19 infection: different points from adults. Pediatr Pulmonol. 2020;55(5):1169-74.

26. Xiong $\sqcup$, Zhou MY, He XQ, Wu Y, Xie XL. The role of human Coronavirus infection in pediatric acute gastroenteritis. Pediatr Infect Dis J. 2020;39(7):645-9.

27. Zeng LK, Tao XW, Yuan WH, Wang J, Liu X, Liu ZS. [First case of neonate with COVID-19 in China]. Zhonghua Er Ke Za Zhi. 2020;58(4):279-80. Chinese.

28. Zhang C, Gu J, Chen Q, Deng N, Li J, Huang L, et al. Clinical and epidemiological characteristics of pediatric SARS-CoV-2 infections in China: A multicenter case series. PLoS Med. 2020;17(6):e1003130.

29. Zhou Y, Yang GD, Feng K, Huang H, Yun YX, Mou XY, et al. [Clinical features and chest CT findings of coronavirus disease 2019 in infants and young children]. Zhongguo Dang Dai Er Ke Za Zhi. 2020;22(3):215-20. Chinese.
30. Li F, Feng ZC, Shi Y. Proposal for prevention and control of the 2019 novel coronavirus disease in newborn infants. Arch Dis Child Fetal Neonatal Ed. 2020 Mar 4:fetalneonatal-2020-318996

31. Hong H, Wang Y, Chung HT, Chen CJ. Clinical characteristics of novel coronavirus disease 2019 (COVID-19) in newborns, infants and children. Pediatr Neonatol. 2020;61(2):131-2.

32. Zhu H, Wang L, Fang C, Peng S, Zhang L, Chang G, et al. Clinical analysis of 10 neonates born to mothers with 2019-nCoV pneumonia. Transl Pediatr. 2020;9(1):51-60.

33. Cao Q, Chen YC, Chen CL, Chiu CH. SARS-CoV-2 infection in children: transmission dynamics and clinical characteristics. J Formos Med Assoc. 2020;119(3):670-3.

34. Zhou F, Yu T, Du R, Fan G, Liu Y, Liu Z, et al. Clinical course and risk factors for mortality of adult inpatients with COVID-19 in Wuhan, China: a retrospective cohort study. Lancet. 2020;395(10229):1054-62.

35. World Health Organization (WHO). Multisystem inflammatory syndrome in children and adolescents with COVID-19. Genève: WH0; 2020 [updated 2020 May 15; cited 2020 Sep 23]. Available from: https://www.who.int/publications-detail/multisystem-inflammatorysyndrome-in-children-and-adolescents-with-COVID-19

36. Sun D, Li H, Lu XX, Xiao H, Ren J, Zhang FR, et al. Clinical features of severe pediatric patients with coronavirus disease 2019 in Wuhan: a single center's observational study. World J Pediatr. 2020;16(3):251-9.

37. Lu X, Zhang L, Du H, Zhang J, Li YY, Qu J, et al.; Chinese Pediatric Novel Coronavirus Study Team. SARS-CoV-2 Infection in Children. N Engl J Med. 2020;382(17):1663-5.

38. Borges do Nascimento IJ, Cacic N,Abdulazeem HM, von Groote TC, Jayarajah U, Weerasekara I, et al. Novel coronavirus infection (COVID-19) in humans: a scoping review and metaanalysis. J Clin Med. 2020;9(4):941.

39. Conselho Federal de Enfermagem (COFEN). Cofen publica nota de esclarecimento sobre o Coronavírus (COVID-19). Brasília (DF): COFEN; 2020 [citado 2020 Set 30]. Disponível em: http://www.cofen.gov.br/cofen-publica-nota-de-esclarecimento-sobre-0-coronavirusCOVID-19_77835.html 